\title{
Continuous extrusion and rolling forming technology of copper strip manufacture
}

\author{
Xinbing Yun a , Mo Zhou, Tian Tian, and Ying Zhao \\ Engineering Research Center of Continuous Extrusion, Ministry of Education, Dalian Jiaotong \\ University, Dalian 116028, China
}

\begin{abstract}
Continuous extrusion and rolling technology was proposed as a new strip production technology. It finished hot rolling process using the waste heat of the continuous extrusion forming. The continuous extrusion and rolling forming process was simulated by DEFORM-3DT software. The influence of extrusion wheel velocity and strip size on the continuous extrusion and rolling forming process was analyzed. The experiment was carried out according to optimized results of numerical simulation, the microstructure and property of copper strip were fine.
\end{abstract}

\section{Introduction}

Continuous extrusion and rolling forming technology was a new and environmental manufacturing technology. It combined continuous extrusion process and rolling process in a row. The principle of continuous extrusion and rolling process was that oxygen-free copper plates or strips was presented by continuous extrusion with the temperature of the strips about 400 to $600{ }^{\circ} \mathrm{C}$ in the exit of die [1], there was a distance between continuous extrusion machine and rolling mill, and strips supplied by continuous extrusion could be rolled down until reaching a certain length with the temperature about 360 to $400{ }^{\circ} \mathrm{C}$ in the entrance of rolls.

Compared with traditional processes of cold rolling after continuous extrusion, the continuous extrusion and rolling process method has the following advantages [2-5]. Firstly, in this process, the frictional resistance for energy dissipation was transferred into the deformation driving force, and deformation heat and friction heat were used to reach the thermal deformation temperature of billet, so the heating process was eliminated. Secondly, both the continuous extrusion and rolling completely achieved the thermal deformation of the billet, during which dynamic recrystallization occured. Therefore, the grain was significantly refined and the material property was improved; however, the size of the billet was nearly the same as that of the finished product, thus reducing the workforce of the finishing process.

\footnotetext{
${ }^{\text {a }}$ Corresponding author: yunxb@djtu.edu.cn
}

This is an Open Access article distributed under the terms of the Creative Commons Attribution License 4.0, which permits unrestricted use, distribution, and reproduction in any medium, provided the original work is properly cited. 


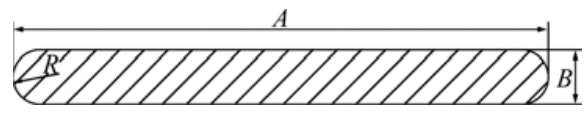

Figure 1. Cross-sectional shape of the rolled strip.

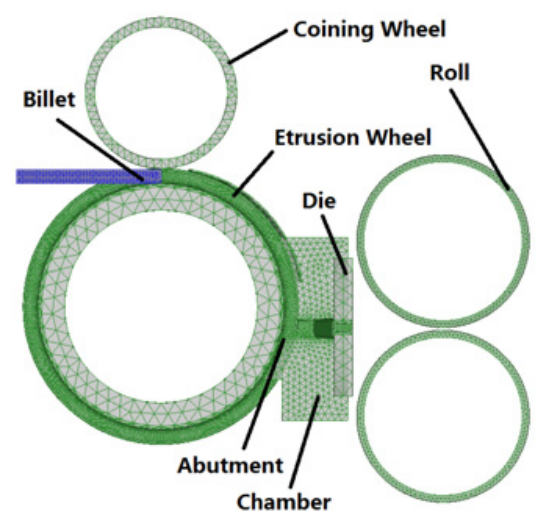

Figure 2. Finite element geometric model.

Xinbing Yun et al. proposed the principle of continuous extrusion and rolling technology by theoretical calculation and numerical simulation [6]. It did not consider the deformation regularity of billet in the process with variation of the technological parameters.

In this work, the finite model of continuous extrusion and rolling process was established by using DEFORM-3D software platform in order to simulate the whole process, and the deformation regularity of billet was analyzed in the continuous extrusion and rolling process with variation of the technological parameters, such as the influence of extrusion wheel velocity and strip size.

\section{Numerical simulation of continuous extrusion and rolling}

The DEFORM-3D software was used for the numerical simulation of continuous extrusion and rolling process of copper strips. The influences of extrusion wheel velocity, rolling reduction and strip size on the continuous extrusion and rolling forming process were analyzed. The deformation regularities of temperature of billet, torques of extrusion wheel and rolls and rolling force were compared and studied. The size of a copper strip produced by continuous extrusion process was depicted in Fig. 1.

The finite-element simulation model which was established by using TLJ400 continuous extrusion machine and the roll with diameter of $250 \mathrm{~mm}$ as the model was depicted in Fig. 2, where the representative geometry parameters were indicated. To save time and reduce the computer storage capacity, $1 / 2$ of the integral model was used for the simulations based on the symmetry [7, 8].

In this work, the die and other parts were set as rigid bodies. The shear friction driving model was used for the friction between the contact surfaces of the billet and the die. The friction coefficient between the extrusion wheel and the billet was set at 0.95 , whereas the friction coefficient between the roller and the billet was set at 0.35 . By considering the preheating of the cavity, the initial temperatures of tools and die were set at $450^{\circ} \mathrm{C}$ [9-12]. 


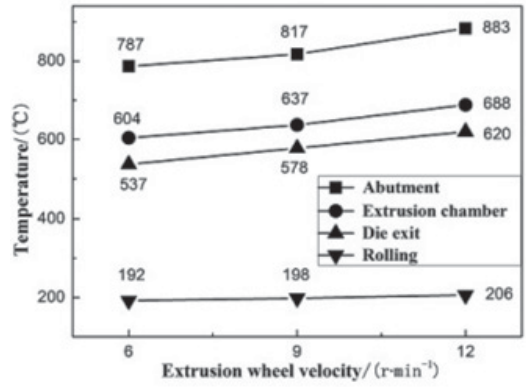

Figure 3. Temperature vs. velocities.

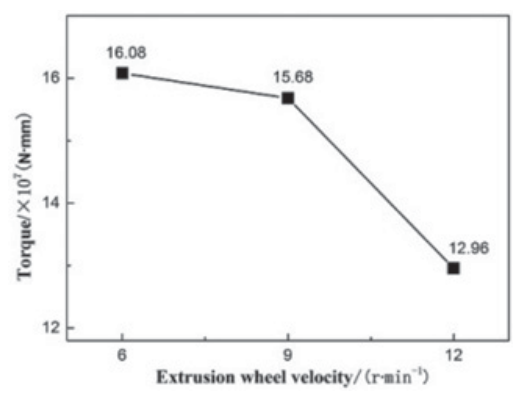

Figure 4. Torque of extrusion wheel vs. velocities.

\section{Simulation results and analysis}

\subsection{The influence of extrusion wheel velocity on the continuous extrusion and rolling forming process}

Extrusion wheel velocity was set to $6 r / \mathrm{min}, 9 r / \mathrm{min}$, and $12 \mathrm{r} / \mathrm{min}$ for the numerical simulations. Comparison of temperature, effective-stress, torque of extrusion wheel and rolling and rolling force were analysed under different extrusion wheel velocities.

It can be observed that the temperature lines in the continuous extrusion and rolling process were escalating trend with extrusion wheel velocity increased in Fig. 3. The temperature of billet in the area of abutment was hottest which was increased from $787^{\circ}$ to $883^{\circ}$, temperature of billet in the area of chamber was ascended from $604^{\circ}$ to $688^{\circ}$, temperature of billet in the area of exit of die was risen from $537^{\circ}$ to $620^{\circ}$, and temperature of billet in the area of rolls was from $192^{\circ}$ up to $206^{\circ}$. What makes increment of temperature of billet was that the speed difference between billet and extrusion wheel become bigger with greater velocity of extrusion wheel, the work from extrusion wheel to qualities of heat of billet was increased, and the extent of plastic transformation of billet was severer with extrusion wheel velocity increased. Due to temperature of billet in the continuous extrusion process was increased, the temperature in the rolling process was also increased, and the abutment and chamber will be suffered more abraded. As a result, it was not advisable to choose overlarge velocity of extrusion wheel for continuous extrusion and rolling process.

In Fig. 4, we recognized that the torque of extrusion wheel would be dropped from $5.44 \mathrm{~N} \cdot \mathrm{mm}$ to $4.80 \mathrm{~N} \cdot \mathrm{mm}$ when extrusion wheel velocity was increased from $6 \mathrm{r} / \mathrm{min}$ to $12 \mathrm{r} / \mathrm{min}$. With increasing of temperature of billet made extent of plastic transformation of billet severer, work of billet to plastic transformation needed from extrusion wheel was reduced.

Because of resistance of strip suffered by rolls decreasing, torque of rolls was also dropped from $16.08 \mathrm{~N} \cdot \mathrm{mm}$ to $12.96 \mathrm{~N} \cdot \mathrm{mm}$ with extrusion wheel velocity increased from $6 \mathrm{r} / \mathrm{min}$ to $12 \mathrm{r} / \mathrm{min}$, as shown in Fig. 5.

We figured out from Fig. 6 that the values of rolling force were all falling trend with extrusion wheel velocity increased. The value of rolling force was decreased from $1060 \mathrm{kN}$ to $804 \mathrm{kN}$. We drew a conclusion that rolling process would become easy with rapider velocity of extrusion wheel, but the rapider velocity of extrusion wheel, the higher temperature of billet in the process, the higher temperature of abutment, the less working life of the moulds.

\subsection{The influence of strip size on the continuous extrusion and rolling forming process}

In the continuous extrusion process, if the strips produced by continuous extrusion had the same width but different thickness, it would led greater extrusion force with thinner the strips. In this part, we 


\section{MATEC Web of Conferences}

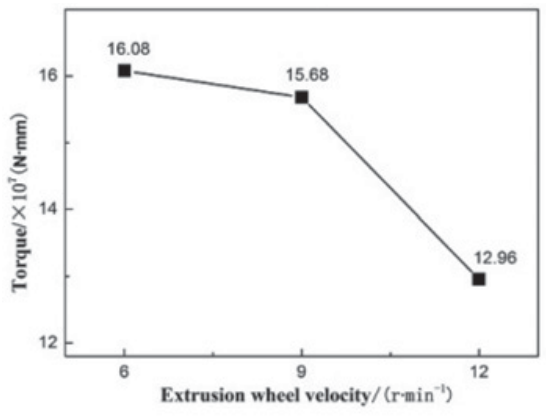

Figure 5. Torque of roll vs. velocities.

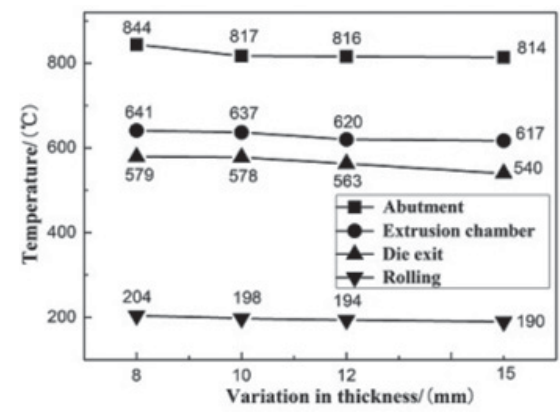

Figure 7. Temperature vs. thickness.

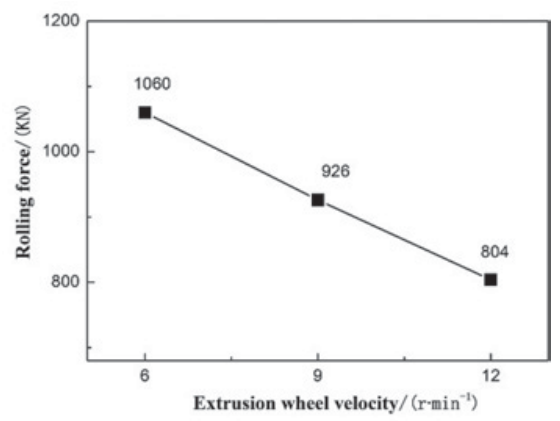

Figure 6. Rolling force vs. velocities.

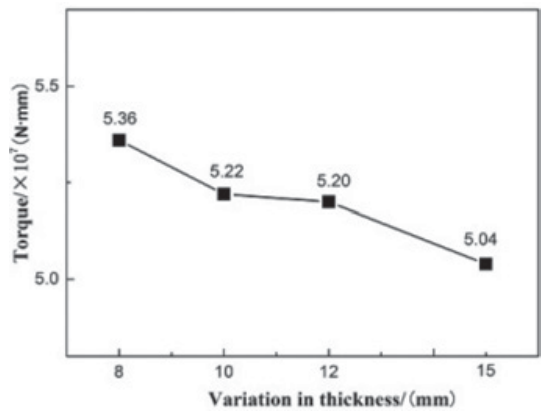

Figure 8. Torque of extrusion wheel vs. thickness.

would find out the transformation regularity that strips of copper would be presented by continuous extrusion process as the size of $120 \times 8 \mathrm{~mm}^{2}, 120 \times 10 \mathrm{~mm}^{2}, 120 \times 12 \mathrm{~mm}^{2}$, and $120 \times 15 \mathrm{~mm}^{2}$, and rolling reduction respectively were $4 \mathrm{~mm}, 6 \mathrm{~mm}, 8 \mathrm{~mm}$ and $10 \mathrm{~mm}$, finally getting the same product with $120 \times 4 \mathrm{~mm}^{2}$.

The temperature of billet fell in the process of continuous extrusion and rolling with thickness of strips increased in Fig. 7. With the thickness of strip billet increased from $8 \mathrm{~mm}$ to $15 \mathrm{~mm}$, it was from $844^{\circ}$ to $814^{\circ}$ in the abutment area, from $641^{\circ}$ to $617^{\circ}$ in the extrusion chamber, from $579^{\circ}$ to $540^{\circ}$ in the exit of the die, and from $204^{\circ}$ to $190^{\circ}$ in the rolling area. The thinner strip billets, the greater extrusion force, the higher temperature of billet.

The values of torque of extrusion wheel were declined as increasing thickness of strips in Fig. 8 . When the thickness was from $8 \mathrm{~mm}$ to $10 \mathrm{~mm}$, and from $12 \mathrm{~mm}$ to $15 \mathrm{~mm}$, value of torque of extrusion wheel was descended, thickness was from $10 \mathrm{~mm}$ to $12 \mathrm{~mm}$, torque line was nearly horizontal.

On the contrary, torque and rolling force were both ascended with thickness of strip increased. Torque of rolls was from $11.08 \mathrm{~N} \cdot \mathrm{mm}$ up to $17.39 \mathrm{~N} \cdot \mathrm{mm}$ in Fig. 9, as thickness of strip increased from $8 \mathrm{~mm}$ to $15 \mathrm{~mm}$. And rolling forces in Fig. 10 were risen from $730 \mathrm{kN}$ to $1224 \mathrm{kN}$. In a word, greater value of thickness of strip, smaller value of torque of extrusion wheel, greater value of torque and rolling force. 


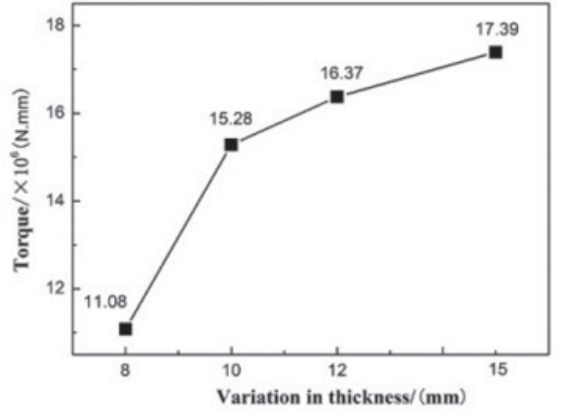

Figure 9. Torque of roll vs. thickness.

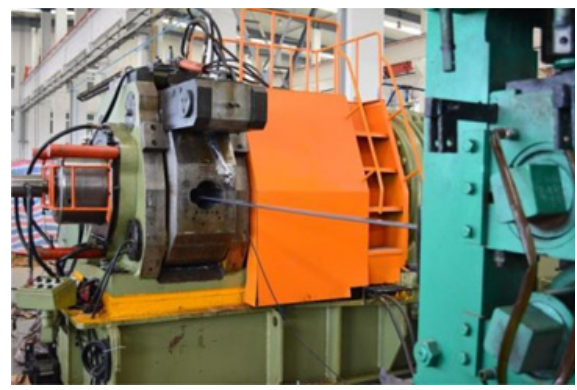

Figure 11. Experiment of continuous extrusion and rolling.

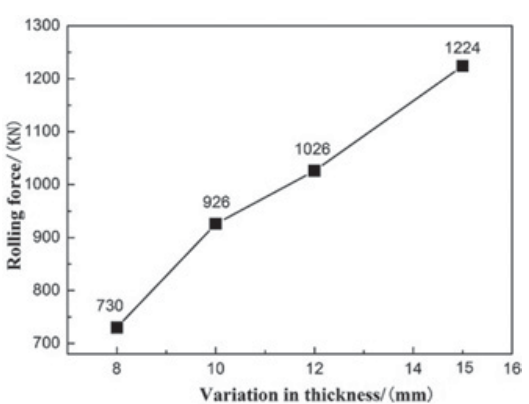

Figure 10. Rolling force vs. thickness.

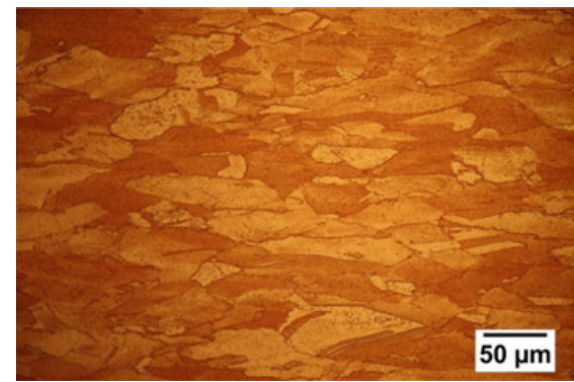

Figure 12. Microstructure of copper strip.

\section{Experimental results}

The experiment of continuous extrusion and rolling process was carried out according to optimized results of numerical simulation. In the experiment, TLJ400 continuous extrusion machine and rolling mill with a diameter of $250 \mathrm{~mm}$ were used for continuous extrusion and rolling process, a diameter of the initial billet of copper was $20 \mathrm{~mm}$, the size of strip produced by continuous extrusion machine was $120 \times 10 \mathrm{~mm}^{2}$, and rolling reduction was $4 \mathrm{~mm}$. In Fig. 11, the experiment field of continuous extrusion and rolling was presented. Microstructure of the product was depicted in Fig. 12, which the grain was fine, and the grain was stretched obviously along the rolling direction and the grain boundary was clear. Its tensile strength was $320 \mathrm{MPa}$, elongation was $27 \%$.

\section{Conclusions}

Firstly, he greater value of extrusion wheel velocity on the continuous extrusion and rolling forming process, the easier work of extrusion wheel and roller, but the higher temperature of billet in the process, the more abraded the abutment would be suffered. Therefore the rapider velocity of extrusion wheel was inapposite.

Secondly, it was easy for continuous extrusion process to present the greater thickness of strip of copper. To obtain the same size of strip from continuous extrusion and rolling process, the strip produced by continuous extrusion has the greater thickness, it needed the greater rolling reduction. Therefore, it would cause the greater load of roller.

The present work was partly supported by National Natural Science Foundation of China (No. 51175055) and Special Research Found for the Doctoral Program of Higher Education (No. 20132124110003). 


\section{References}

[1] C.D. Chu, F.B. Zha, Y.H. Peng, et al., Mechanical Science and Technology 20(4) 556-557 (2001)

[2] Y.L. Cheng, X.B. Yun, J.Y. Yang et al., Journal of Plasticity Engineering 21(5) 77-81 (2014)

[3] H.Y. Zhang, J.B. Zhang, B. Xie, Casting Forging Welding (23) 213-215 (2010)

[4] X.B. Yun, M.L. Yao, Y. Zhao, et al., Joural of Plasticity Engineering 18(4) 2-5 (2011)

[5] P.Y. Wu, S.S. Xie, H.Q. Li, Transactions of Nonferrous Metals Society of China 17(2) 280-286 (2007)

[6] X.B. Yun, W. You, Y. Zhao, et al., Transactions of Nonferrous Metals Society of China 23(4) 1108-1113 (2013)

[7] X. Chen, X.B. Yun, Y. Zhao, et al., Journal of Plasticity Engineering 17(2) 68-72 (2010)

[8] X. Cao, Y.W. Liu, J.Y. Pei, Forging \& Stamping Technology 38(5) 91-95 (2013)

[9] B. Li, X.J. Yao, X.B. Yun, et al., AIP Conf. Proc. 1532 918-923 (2013)

[10] Y.H. Kim, J.R. Cho, K.S. Kim, et al., Journal of Materials Processing Technology, 153-157 (2000)

[11] Z.X. Fan, X. Cao, B.Y. Song, Journal of Plasticity Engineering 15(4) 136-141 (2008)

[12] Y.H. Kim, J.R. Cho, K.S. Kim, et al., Journal of Materials Processing Technology, 671-675 (1998) 